\title{
The Effect of Integrating Computer-Assisted Language Learning Materials In L2 Reading Comprehension Classroom
}

\author{
Hussein Meihami ${ }^{1, *}$, Zeinab Varmaghani $^{2}$ \\ 1Department of English Language Teaching, Ghorveh Branch, Islamic Azad University, Ghom-Iran \\ 2BA Student of Primary Education, Ghorveh Branch, Islamic Azad University, Gho veh, Iran \\ *E-mail address: hussein.meihami@yahoo.com

\section{ABSTRACT} \\ With the turn of the century, Computer-Assisted Language $2 \mathrm{e}_{\mathrm{a}}$ (CALL) as got the center \\ of attention in second and foreign language learning (ESL/EFI) riggen with the technology of the

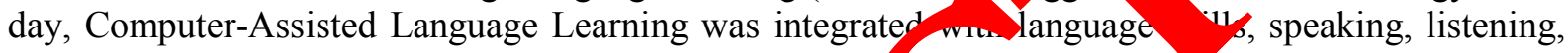 \\ writing, and reading to serve as the medium of teaching ar d learning in L2 classrooms. This paper is an \\ investigation of the effect of integrating CALL materials L2 reading cpmprehension classrooms. The \\ study was conducted in two classes each included 30 st nts attendi g a course on English reading \\ comprehension at the Azad University in Qazvin, Iran. Th mpari on between the experimental and \\ the control group pinpoint that CALL materials ave reading comprehension skill among EFL low \\ advanced students. It was also revealed that mo stu haye positive attitude toward CALL. The \\ results suggests that using CALL materials both in te ching and learning reading comprehension of L2 \\ is beneficial in allowing learners to $m$ nproven nts in reading comprehension.
}

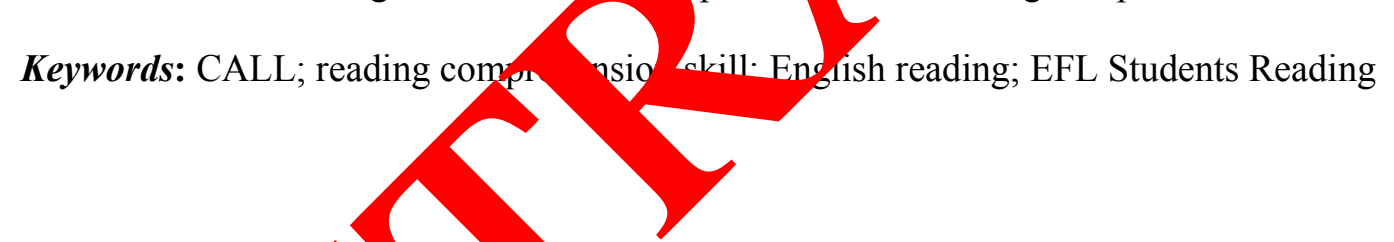

\section{INTRODUCT O.}

When red a the possible roles of computer tools, instructors were cynical about computers rep ng hun interaction in teaching second and foreign language. They pointe that viti s that involve discussion, role play, sharing opinions, and seeing lan age fill a co municative purpose in general presented ideal scenarios for students to inter w human being (Luiz A. Amaral and Detmar Meurers, 2011). They argued that lea ng to communicate in a foreign language implies learning to negotiate meaning, understan social behavior, and observing different body language strategies (Andrews, R., Burn, A., Leach, J., Locke, T., Low, \& G., Torgerson, C. 2002).

The instructors interviewed were skeptical about the possibility of computers replacing humans in this respect. However, they were very receptive to the idea of automatic support tools to practice receptive skills, reinforce the acquisition of language forms, propose remedial work, and raise linguistic awareness in general (Chapelle, 2005). This situation can be seen as an excellent motivation and opportunity for developing CALL tools that provide personalized feedback on learner errors and foster linguistic awareness of relevant language forms and categories. But traditional CALL systems provide only limited 
exercise types, such as multiple choices, matching, point-and-click, or simple form filling. Moreover, their ability to provide feed-back is restricted to letter-by-letter feedback or specific hand-specified feedback messages based on matching the learner response with a pre-stored target answer, either directly or by using regular expressions (Hansol, 2000). There is thus a clear need for linguistic modeling to improve the ability of CALL systems to handle more complex exercise types, and to provide detailed individualized feedback (Luiz A. Amaral and Detmar Meurers, 2011).

CALL is a relatively new and rapidly evolving academic field that explores the role of information and communication technologies in language learning and teaching. It jorundes a wide range of activities and initiatives in materials development, pedagogical ractica, d research. As Chambers \& Davies (2001) state, however, CALL includes highl teractive à communicative support for listening, speaking, reading, and writing, including ex vive use ff the Internet. Materials development, pedagogy, and research in this fie d have de ope in intellectual sophistication to the point where CALL should be consi red as inde ndent academic field of study as stated by Chapelle (2002).

CALL, is sometimes regarded simply as a sub-section of computer isted instruction (CAI), but because CALL deals specifically with languag ning, it is oth inherently multidisciplinary and academically substantive (Egbert, J. ar. Han Smith, 2003).CALL can be said to belong to the field of applied language studie anu, within th $/$ most closely related to second language acquisition (SLA), which itself a rapid) evolving discipline (Luiz A. Amaral and Detmar Meurers, 2011). As Eu CALL state CALL and SLA are related to sociolinguistics, pragmatics, discourse analysis, psycholi guistics. Computer assisted language learning is a new field in both the computer suistics sciences. Linking both fields, it offers good promises to teachers ists, and computer researchers. With the growing sense of unity between linguists an $\mathrm{cos}_{\mathrm{s}}$ scientists, some of the mysteries of language acquisition will be unravelad, which an help provide more effective and principled language teaching (Kenning \& $\mathrm{K}$ enn

The linguist can provid the retical as sumptions of language learning, the efficient

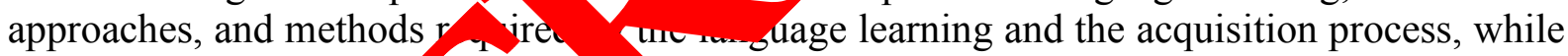
the computer scientist co help prov vophisticated means to meet the requirements generated by those approaches nd hods (Ha s $\mathrm{sol}, 2000)$. There are many peripheral applications for computers in the eadcation domain. Language testing, language research, and school management, f instance, all o scopes for computer applications. From the point of view of TEFL, LL grams help improve learning speed, individualized instruction, authenticity, e ncy, an administration. Linguists view CALL as a new device for testing current d d destoping new ones accurately (Hasnsol, 2000).

1.1. om Lanted Language Learning Through Time

C. can be divided into three main periods as follow (as cited in A. Marzban, 2011):

\section{1. 1 Behaviorist CALL}

In the 1960's and 1970's, the first form of computer-assisted Language Learning featured repetitive language drills, the so-called drill-and-practice method. It was based on the behaviorist learning model and as such the computer was viewed as little more than a mechanical tutor that never grew tired. Behaviorist CALL was first designed and implemented in the era of the mainframe and the best-known tutorial system, PLATO, ran on its own special 
hardware. It was mainly used for extensive drills, explicit grammar instruction, and translation tests (Ahmad K., Corbett G., Rogers M. and Sussex R. 1998).

\section{1. 2. Communicative CALL}

Communicative CALL emerged in the 1970's and 1980's as a reaction to the behaviorist approach to language learning. Proponents of communicative CALL rejected behaviorist approaches at both the theoretical and pedagogical level. They stressed that CALL should focus more on using forms rather than on the forms themselves. Grammar should be taught implicitly and students should be encouraged to generate original utterances instead of m ing prefabricated forms (Jones, C. \& Fortescue, S. 1987). This form of computer-ba ed instruo corresponded to cognitive theories which recognized that learning was a crea process discovery, expression, and development. The mainframe was replaced by sona smput is that allowed greater possibilities for individual work. The communic ative SALL roms provide skill practice in a non-drill format through language games, ula $\mathrm{Or}, \mathrm{r}$ ad $/ \mathrm{ig}$ and text reconstruction, word processors, desk-top publishing, sp a.m a gramp ar checks programs, as used for instance in process writing.

\section{1. 3. Integrative CALL}

Communicative CALL was criticized for $y$ ing the comput $r$ in an ad hoc and disconnected fashion and critics charged that thi use of the computer made "a greater contribution to marginal rather than central elem " of lan guage learning (Kenning \& Kenning, 1990). Teachers have moved away from a cos con of commicative language teaching to a socio-cognitive view that emph real language use in a meaningful, authentic context. Integrative CALL seeks both to in egr w various skills of language learning (listening, speaking, writing, and reading) and integrate technology more fully into language teaching (Warschauer, M., \& Ycan D., 15 8). To this end the multimedia-networked computer provides a range $g$ form tional, communicative, and publishing tools that are potentially available to ever tud approach is integrative CALL, which is based on multimedia compute and the rnet. These technological developments have brought text, graphics, sound an tion and to be accessed on a single inexpensive computer. These resources am a l link and called 'hypermedia', enabling learners to navigate through CD-ROMS and he Internet at Yown pace and path, using a variety of media.

\section{2. CALL ih ching i nguage Skills}

$\mathrm{g}$ the $\mathrm{d}$ cades, theory and practice in language learning and language teaching chan ed in sone fundamental ways. Kelly (2006) with the development of new tech. has been an attendant interest in applying these new technologies in the educat arena, and in making predictions of how they would affect the educational future of our clà boms and students. In forecasting the technological future, it is important to consider what the capabilities of educational computing are, and what can be done in the language classroom that will remain current, even if the technology does not. There is nothing certain about the future of technology, except that it will no doubt become more ubiquitous and powerful (cited in Celce-Murcia, 2001).

G. Wiebe and K. Kabata (2010) did a survey on how is the effect of CALL on reading comprehension on a group of students. The findings of their research revealed the fact that CALL materials if be used in constant way could be significant in improving students reading comprehension. 
Brinton and Holten (1997) state that media help us to motivate students by bringing a slice of real life into the classroom and by presenting language in its more complete communicative context. Media can also provide a density of information and richness of cultural input not otherwise possible in the classroom, they can help students to process information and free the teacher from excessive explanation, and they can provide contextualization and a solid point of departure for classroom activities.

\section{METHODOLOGY}

\section{1. Research Hypothesis}

For the purpose of this research a Null hypothesis was employed: Integrat comput assisted language learning material has no effect on improving Readin compra sion of Iranian low advanced EFL learners.

\section{2. Participant}

Sixty Iranian low advanced students of Azad Univer ty Qazvin, li 1, all male and with age range 19 to 22 participated in this study. During year, University of Qazvin provided its students with some free yet qualified langy age learning pro $\mathrm{m}$ such as: Listening Comprehension Program, Reading Comprehension rogram, Essay Writing Program, and so on. One of that provided program as it was said wa eading Cor pprehension Program (RCP) in which students attended classes that focused on tea $\mathrm{g}$ and le rning RC. In April 2013, 177 students registered in the RCP. A proficie test on comprehension was held that raveled students' current level of proficiency, Dan the obtained results, sixty students were in low advanced level, fifty five students re in per intermediate, thirty nine were in intermediate level, and twenty thre dents $\mathrm{w}$ re in pre intermediate level of proficiency. For the purpose of this study sixty lrant low ac anced students were chosen and they were divided into an experimental g. $(5-20$ ) and a control group $(\mathrm{N}=30)$. The experimental group (from now on EG mo a ding $\mathrm{III}$ a class that was under the medium of CALL materials, while the co group (now on CG) was attending in a traditional class of reading comprehen on. RCP tok two months, sixteen sessions. Two experienced teachers were cal to give instruction to the students in both groups. The teacher of EG was experienc a in ying CAL $n$ reading comprehension classroom, while the other teacher was experie in pavin comprehension methodology in L2 teaching and learning.

\section{3.}

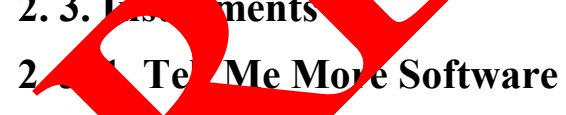

rder to providing the necessary CALL materials for students of experimental group Tell Me s Software was used. This software had the needed qualification for both teaching and learning English Reading Comprehension. The following are some of this software features:

\section{3. 1. Different category of reading texts}

This program provides learners with different reading texts such as: Cultural Workshop, Political Workshop, Technology Workshop, Social Workshop, and so on. Using this software, teacher is free to choose texts for his classroom. 


\section{3. 1. 2. Different reading text within different category}

Within each category there are lots of texts in relation with that category so the teacher is able to select several texts which have nearly the same gist. Fig 1 illustrating this feature:

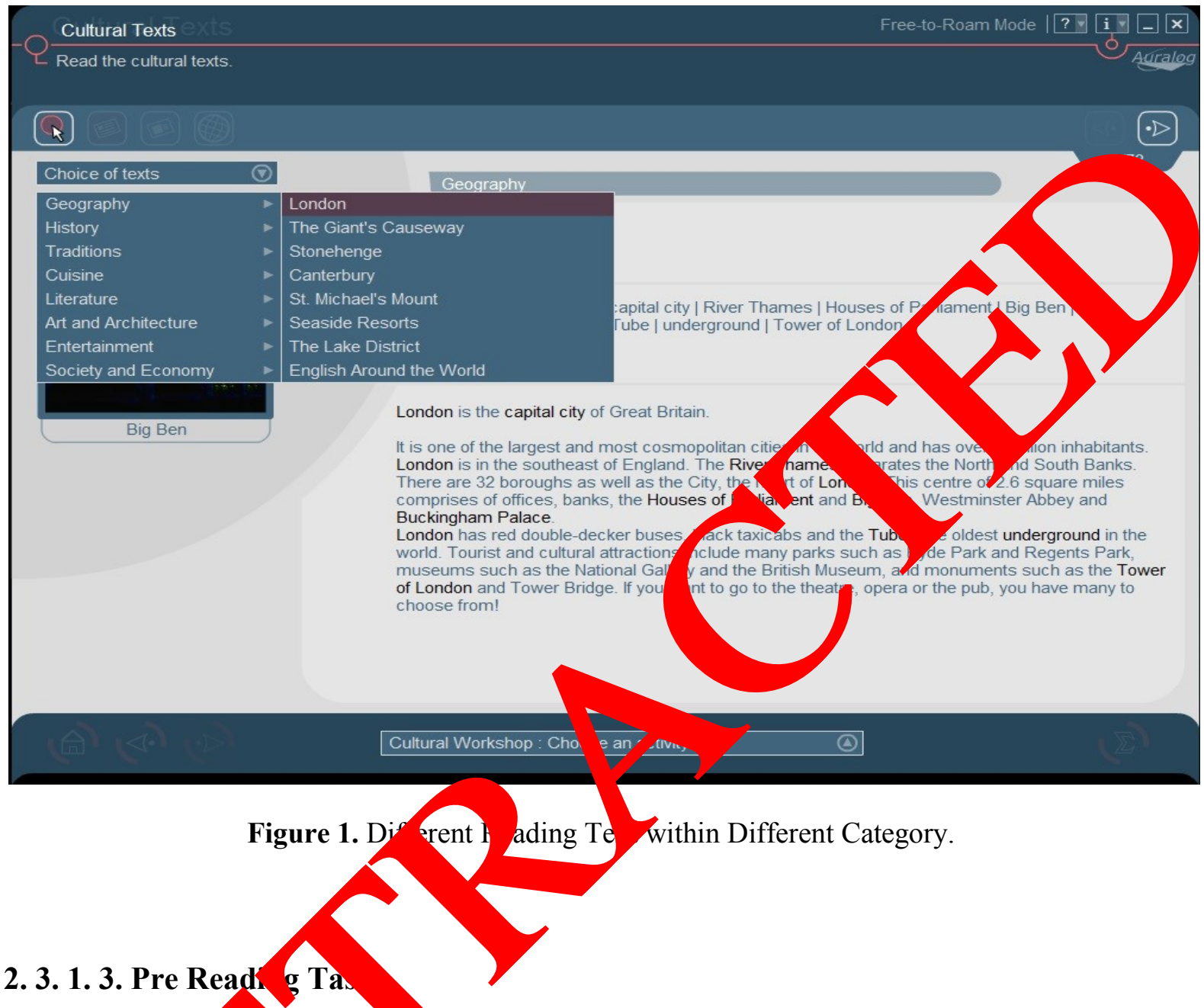

In this sechon the softwa eveloper has provided some pre reading tasks like text gist and the sum rizati of the text for students to work on it and to trigger their background knowledge. Th ". readi g tasks help students to start their reading with more considerate eyes.

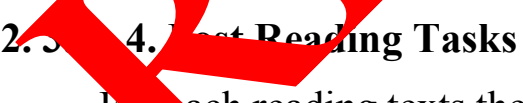

F ach reading texts there are some post reading tasks that help students to render their new obtan information and to foster their ability in communication about the topic of the reading. 


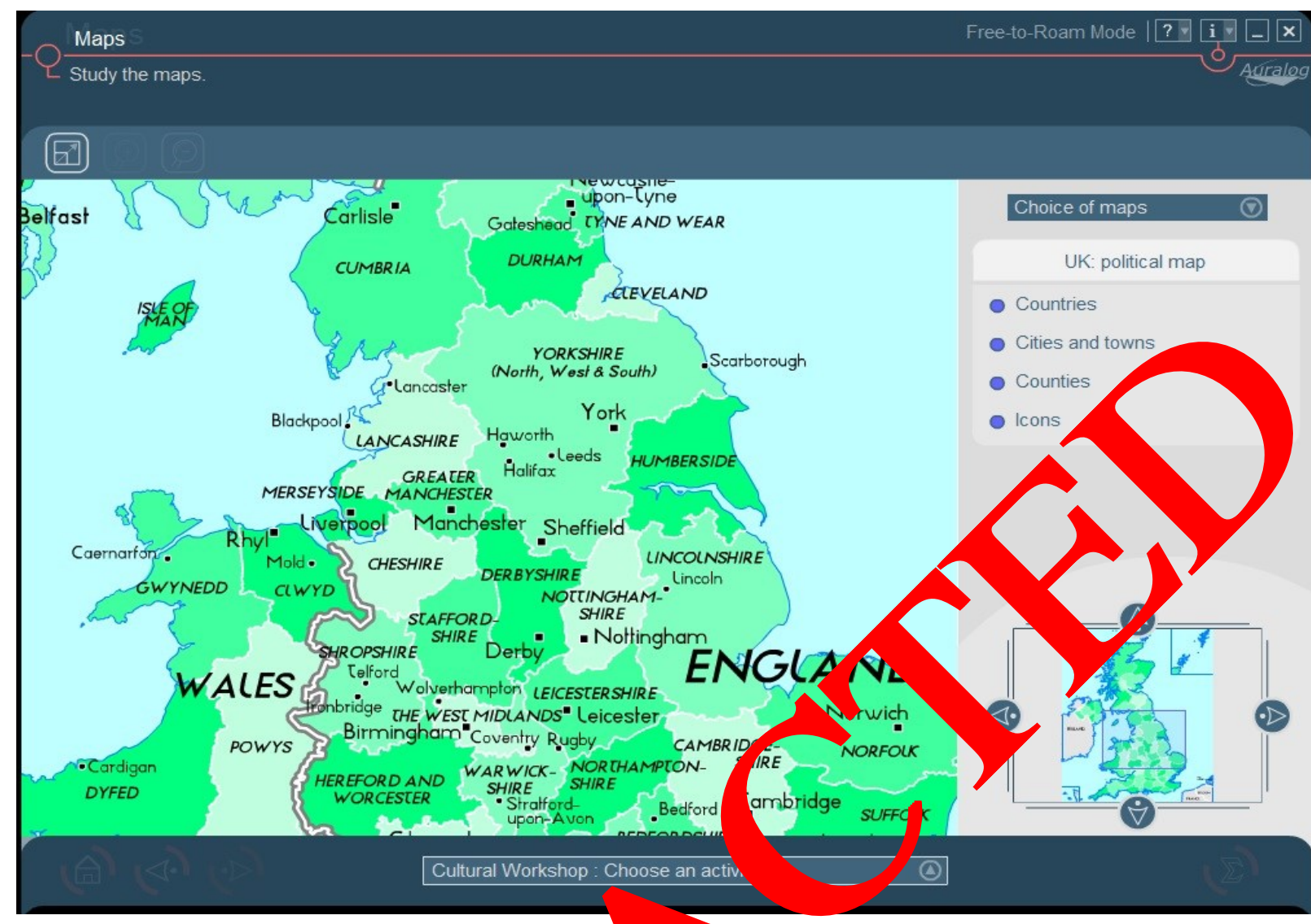

Figure 2. Pos Re? ility sks.

\section{3. 2. Proficiency Test}

Prior to the start of 1e prog a pronciency test was conducted to divided students to different proficiency

\section{3. 3. Pretest $P$ test Des}

For test $\mathrm{g}$ the 11 hypotbesis of this research a pretest posttest design was employed.

\subsection{4. $\mathrm{CnSS} 17$}

In or er to imp ove the accuracy of analyzing date SPSS 17 was used.

\section{4. PI vire}

A Re ding Comprehension Program was announced in Azad University of Qazvin, Iran, in April 2013. Sixty Iranian low advanced students all male and with age range of 20 to 23 participated in this research. Their proficiency level was confirmed by the proficiency test conducted in the beginning of the program. They were divided equally into an experimental group $(\mathrm{N}=30)$ and a control group $(\mathrm{N}=30)$. The experimental group was attended in a reading comprehension whose materials were taught through the medium of computer-assisted language learning. When they attended in their class for the first time, a pretest test was conducted. From the second session of the class to one the last, they were under the training of reading comprehension through CALL. Tell Me More Software was the selected CALL 
material for this purpose. The experimental group was attending in a computer libratory included 30 computers. The Tell Me More Software was installed on all of computers. Each session and after students run the Tell Me More Software the teacher in a quite conversing manner with his students selected a text for working on it during the session. The class first went through the pre reading tasks that Tell Me More Software provided. By so doing, first the student brought their background knowledge to their mind and then shared it with their fellows. When they talked about the topic, the teacher read the text for them for once and then student were given 20 minutes to work on the text. For example the Tell Me More Software provided a Text to Speech section that made students able to listen and check pronunciation and maning.

After these activities, the teacher started to work on post reading tasks. Tb ese kim of tasks helped students to foster what they have already learnt in the reading s ion. Tell More Software also provided some reading comprehension questions in relation the tex After students answer them, they had the facilities to check their nswer, to th ir problematic part, and to see their scores. In the final session, sixteen's sion, post t was conducted.

In the control group the procedure was a little bit differe $c$. There the same texts but paper based, the same pretest posttest reading comprehe $\mathrm{S}$ and the se time of the class. On the other hand, the way reading texts were taught $\mathrm{s}$ difh $\mathrm{t}$ from the experimental group. There was no pre reading section for the studer on G, so th sofwarded directly to the text itself. The teacher was the only source for the pronunciation, maning, and knowledge about the text. When students finished reading they d very little conversation on it and then they obliged to answer the text questions. There we vo feedba ks on the responses. At the final session the posttest was conducted.

\section{RESULT}

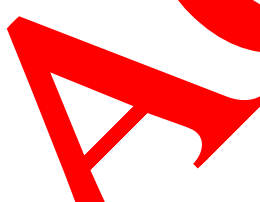

After the collection of reg ared dat the following results obtained. Table 1 is indicating the descriptive s.ntio throum groups.

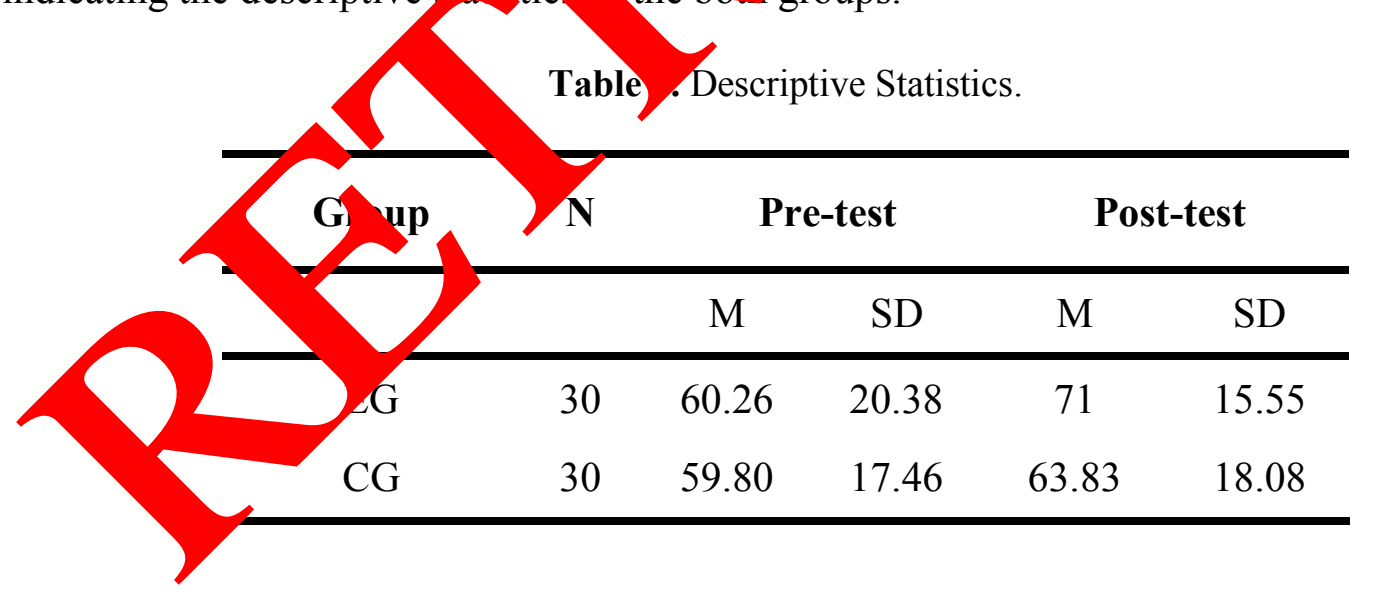

The results show that in the pretest time the means score of the two groups, $E G=60.26$, $\mathrm{CG}=59.80$, were nearly the same. The empirical reason for this sameness in the pretest of the both groups can be related to the effectiveness of the proficiency test in placing students into their suitable proficiency levels. Nevertheless, the means score of posttest of the both classes aren't the same as they were in the pretest. The mean score of EG whose students were under the training of reading comprehension through computer-assisted language learning materials 
was 71 in the posttest time, on the other hand, the mean score of CG whose students attended in a traditional class of teaching reading comprehension was 63.83 in the posttest time.

The mean score of EG is 7.17 scores higher than the CG in the posttest time. These results show that students reading comprehension improved more in the EG in which the CALL materials used. For addressing the research hypothesis in a more accurate way Tests of Between-Subjects Effects was conducted and its results is illustrated in Table 2.

Table 2. Tests of Between-Subjects Effects.

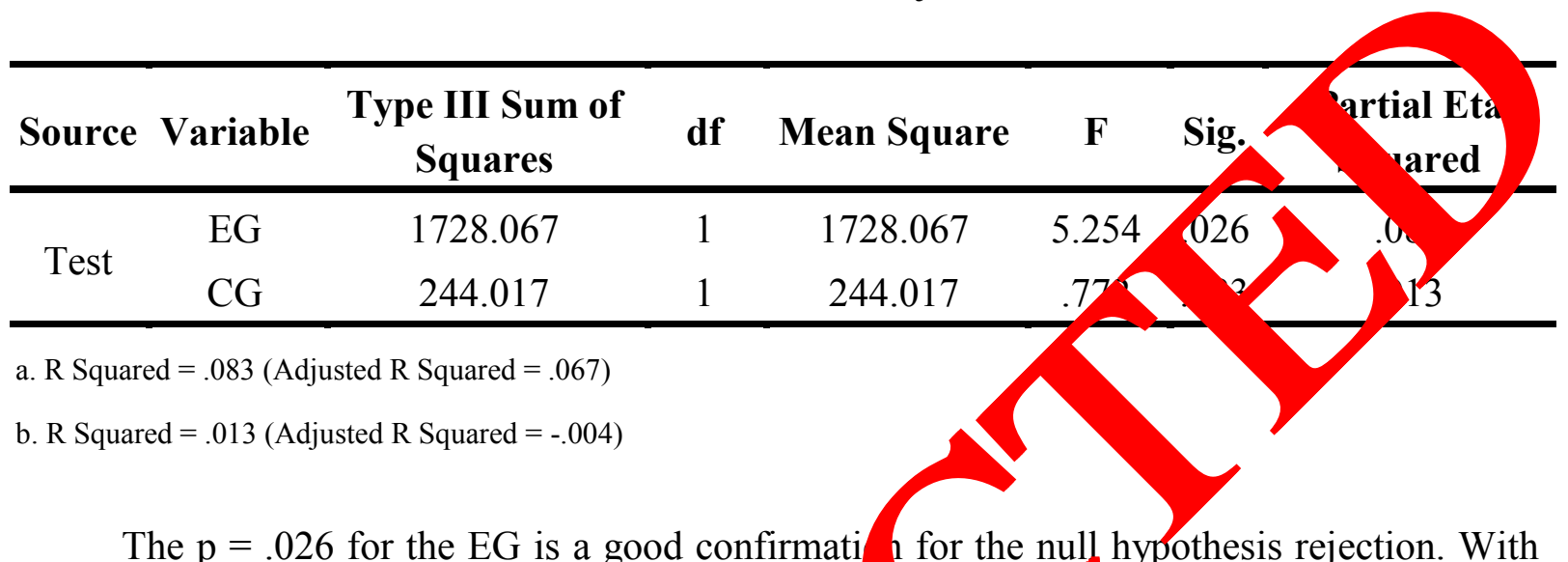
the rejection of the null hypothesis one can consider is fact that 1 sing CALL materials has a significant effect on teaching and learning English ling C mprehension of Iranian EFL low advanced learner. Although the means have alrumy informed us about this fact, the Tests of Between-Subjects Effects is a good o num for this fact.

\section{CONCLUSION}

The aim of this sty dy was vvestigate the effect of integrating CALL materials in English Reading Com ansion of low advanced students. The results of the study showed the implem tatio $C$ CALL materials in the reading comprehension classes had a significant effect omimprovin is skill in EFL situation.

The stur $y$ is co firmed th previous done researches in relation with CALL in different second lansu. Je ming ills. For mentioning some, G. Wiebe and K. Kabata (2010) CALL materials could ignifi ant in improving reading comprehension of students. Kelly (2006) foun ou at CA aterials could be effective in language learning skills and especially re g co iprehension.

section the differences between the means score of the groups indicated the fact that using CALL materials in reading comprehension classes the students could make benefits of at and improve their reading comprehension and it is maybe because of this reason that in this CALL materials there were introduced lots of pre/ post reading tasks that could help students in grabbing the final comprehension of the texts.

On the other hand, when the teacher be the only source of the knowledge in the class, he is probably able to answer to few of student's questions, so the interaction among the students in relation with the reading comprehension was decreasing and they weren't able to improve their reading comprehension as EG students did. Being cleared the promises of CALL materials in reading comprehension, CALL material should be one of the first consideration for language planer and teachers to use it much more than before in their reading comprehension classes. 


\section{References}

[1] Andrews, R., Burn, A., Leach, J., Locke, T., Low, G., Torgerson C. (2002). A systematic review of the impact of networked ICT on 5-16 year olds' literacy in English. In: Research Evidence in Education Library. London: EPPI-Centre, Social Science Research Unit, Institute of Education, University of London.

[2] Chambers, A., Davies, G. (Eds.). (2001). ICT and Language Learning: A European Perspective. Lisse: Swets \& Zeitlinger.

[3] Hansol-Smith (2000). Computer assisted language learning: A client's view. Journal, 7 (4), 67-81.

[4] Net Day Survey. (2001). "The internet, technology and teachers" - ex ytivo mmary May 2001. Available from http://www.netday.org/anniversary_sury cy.htp

[5] Pelgrum, W. J. (2001). Obstacles to the integration of ICT in exau n esults rem a worldwide educational assessment. Computers \& Education $5 / 2), 178$.

[6] Nagata, N. (2009). Robo-Sensei's NLP-Based Error Dete cth and Feedb Generation. CALICO Journal, 26(3), 562-579. [7] Ramsay, A., Mirzaiean, V. (2005) Content-based support for Persity Mearners of
English. ReCALL , 17(1), 139-154.

[8] Reuer, V. (2003). Error recognition and feedbac vith Lexid al Functional Grammar. CALICO Journal, 20(3), 497-512.

[9] Schmidt, R. (1995). Consciousness and Tounouge: A tutorial on the role of attention and awareness in learning. In: h. hidt, (ed.), Attention and awareness in foreign language learning. Ho ' 1 : Univ sity of Hawaii Press, 1-63.

[10] Tschichold C. (2003). Le ally iven err/detection and correction. CALICO Journal, 20(3), 549-559.

[11] Weischedel, R. M Joge, W. N James, M. (1978). An Artificial Intelligence Approach to L guà. Instructio . Artificial Intelligence, 10(3), 225-240.

[12] Willis, D. ran Nillis, J. 9y Doing Task-based Teaching. Oxford: Oxford University Press.

[13] Van den den, K. 2000). Does negotiation of meaning promote reading A sudy of multilingual primary school classes. Reading Research Qua, rly, 35t, 426-43.

[14] Long, Ross S. (1994). The effects of simplified and elaborated texts on eign language reading comprehension. Language Learning, 44(2), 189-219.

[15] Woog, C. (2005). Beginning readers' use of 'talking books' software can affect their reading strategies. Journal of Research in Reading, 28(2), 170-182.

[16] Monirosadat Hosseini, Mohamad Ehsan Taghizadeh, Mohamad Jafre Zainol Abedin, Elham Naseri, (2013). In the Importance of EFL Learners' writing Skill: Is there any Relation between Writing Skill and Content Score of English Essay Test? International Letters of Social and Humanistic Sciences, 6, 1-12. 
[17] Hussein Meihami, Bahram Meihami (2013). Correct I or I Don't Correct Myself: Corrective Feedback on EFL Students Writing. International Letters of Social and Humanistic Sciences, 7, 86-95.

[18] Hussein Meihami (2013). Truscott's Claims in Giving Corrective Feedback: Does It Matter in EFL Writing Context? International Letters of Social and Humanistic Sciences, 8, 8-23.

[18] Hussein Meihami (2013). Text-To-Speech Software: a New Perspective in Learning and Teaching Word Stress, Word Intonation, Pitch Contour, and Fluency of English Reading, International Letters of Social and Humanistic Sciences, 8, 24-33

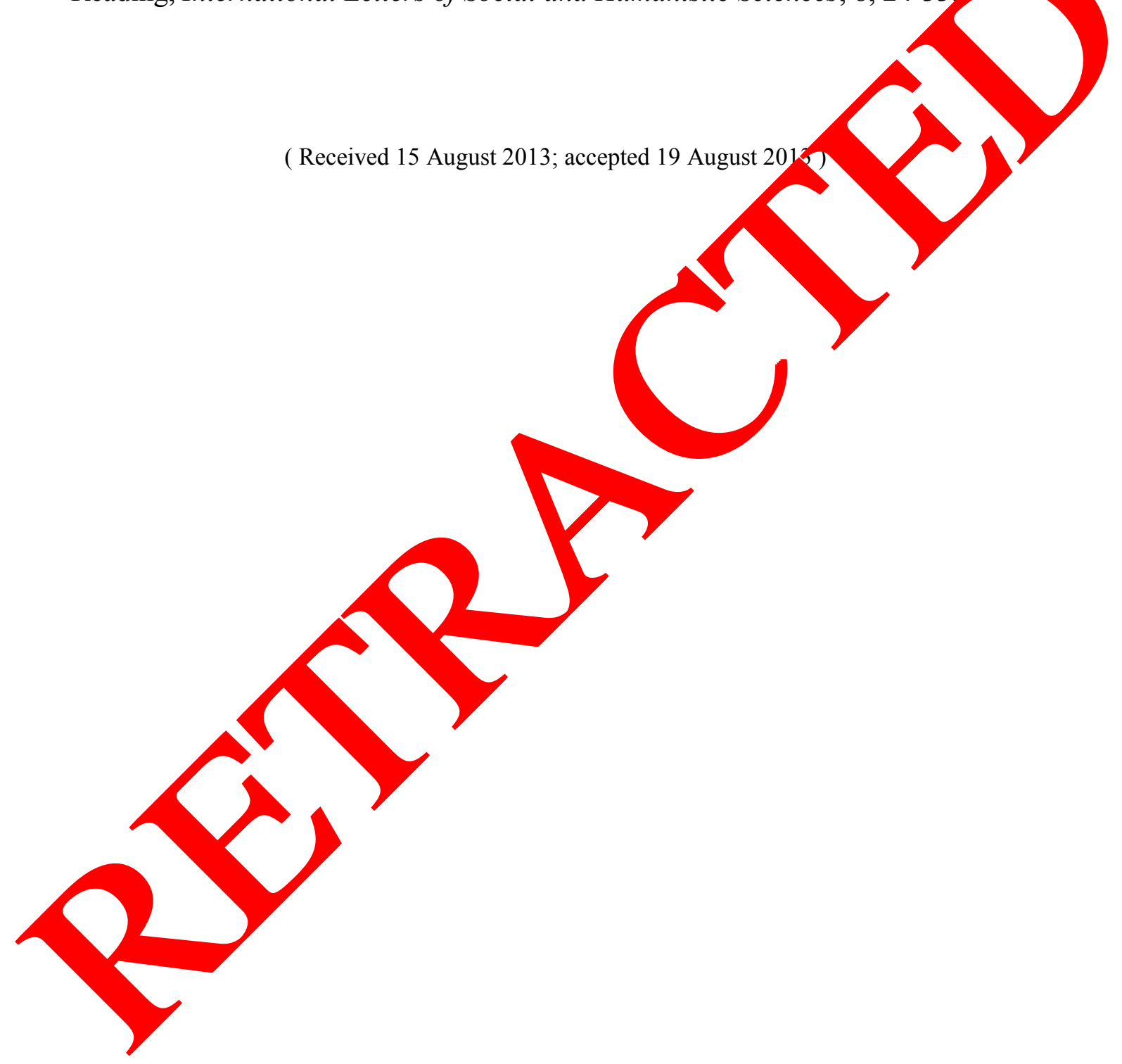

